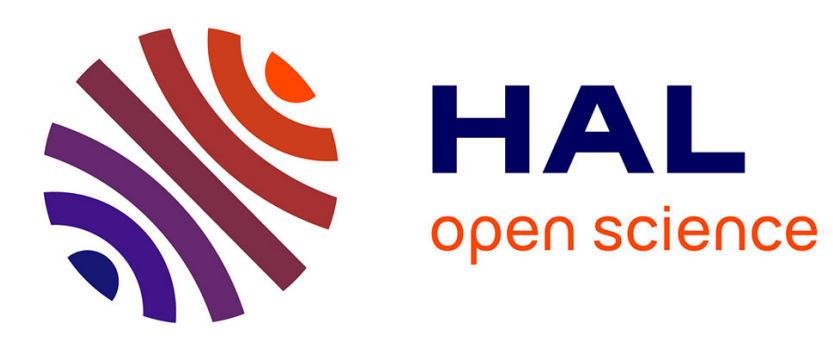

\title{
Design of thermally adaptive composite structures for damping and stiffness control
}

Pauline Butaud, Morvan Ouisse, Gael Chevallier, Emmanuel Foltête

\section{To cite this version:}

Pauline Butaud, Morvan Ouisse, Gael Chevallier, Emmanuel Foltête. Design of thermally adaptive composite structures for damping and stiffness control. SPIE Behavior and Mechanics of Multifunctional Materials and Composites, Mar 2017, Portland, United States. 10.1117/12.2259873 . hal03053051

\section{HAL Id: hal-03053051 \\ https://hal.science/hal-03053051}

Submitted on 10 Dec 2020

HAL is a multi-disciplinary open access archive for the deposit and dissemination of scientific research documents, whether they are published or not. The documents may come from teaching and research institutions in France or abroad, or from public or private research centers.
L'archive ouverte pluridisciplinaire HAL, est destinée au dépôt et à la diffusion de documents scientifiques de niveau recherche, publiés ou non, émanant des établissements d'enseignement et de recherche français ou étrangers, des laboratoires publics ou privés. 


\title{
Design of thermally adaptive composite structures for damping and stiffness control
}

\author{
Pauline Butaud $^{\mathrm{a}}$, Morvan Ouisse ${ }^{\mathrm{a}}$, Gaël Chevallier ${ }^{\mathrm{a}}$, and Emmanuel Foltête ${ }^{\mathrm{a}}$ \\ ${ }^{a}$ Univ. Bourgogne Franche-Comté, FEMTO-ST Institute, CNRS/UFC/ENSMM/UTBM, \\ Department of Applied Mechanics, 24 chemin de l'Epitaphe, 25000 Besancon, France
}

\begin{abstract}
Viscoelastic materials are widely used to control vibrations. However, their mechanical properties are known to be frequency and temperature-dependent. Thus, in a narrow frequency bandwidth, there is an optimal temperature that corresponds to a maximum loss factor and it is tricky to get a high damping level over a wide frequency range. Furthermore, an optimal temperature for a maximum structural damping leads to a poor static stiffness because the peak of the loss factor is obtained during the glass transition when the storage modulus is decreasing. Additionally, in industrial applications, the requirements might change according to the system life-cycle. For instance, the stabilization functions that are used for optronics applications require high stiffness for positioning steps, and high damping for filtering functions. To achieve this goal, engineers usually use several viscoelastic materials with functionally graded damping properties. This allows obtaining a high loss factor over a wide frequency range. This solution is however not adaptive. In order to be able to adjust the properties in real time, we suggest in this paper to use a single material which properties are functionally graded thanks to a non-homogeneous temperature field over the structure. A composite structure has been numerically designed integrating a viscoelastic core and a heat control device. The optimal temperature field has been obtained based on the static and dynamic elastic strain energy densities that reflects the compromise between structural damping over a wide frequency band and high static rigidity.
\end{abstract}

Keywords: damping, viscoelastic, composite, thermally adaptive

\section{INTRODUCTION}

Vibration and noise reduction in dynamic systems can be achieved by a number of means including damping, which can be split in two major categories, namely passive damping and active damping. Their efficiency is qualitatively represented in Fig. 1.(a-b).

Passive damping does not require external energy. The dissipation energy of the structure of interest is increased by adding friction devices, or electromechanics damping, or with viscoelastic materials (polymers) which have the natural capacity to dissipate the vibration energy under deformation. This kind of treatments lead to reliable, low cost and robust vibration control ${ }^{1,2}$. However, the efficiency of the passive damping devices is quite low (Fig. 1.(a)) and can be dependent of the temperature and the frequency.

On the other hand, active control, using for example piezoelectric materials ${ }^{3}$ or adaptive dry friction, ${ }^{4}$ has many advantages such as high precision, performance controllable systems and a quite significant efficiency (Fig. 1.(b)). However active controllers are very sensitive to variations and uncertainties of system parameters ${ }^{5,6}$ even if distributed strategies can enhance performances while increasing robustness ${ }^{7,8}$.

In this work, we want to demonstrate that the tuning of the damping properties of a sandwich composite structure can be achieved through the control of the temperature field of the viscoelastic core and can be adaptated to its frequency environement (Fig. 1.(c)). A Shape Memory Polymer (SMP), which belongs to the class of smart materials, is chosen as viscoelastic core for its high damping power. These materials have found growing interest $^{9}$ throughout the last decades. The SMPs have the ability of changing their shape in response to an external stimulus, most typically thermal activation. It turns out that efficient Shape Memory effects are associated to fast transitions between stable glassy and rubbery states with large elasticity gap, inducing high loss factor

Further author information: (Send correspondence to M. Ouisse.)

E-mail: morvan.ouisse@femto-st.fr 
values at glass transition ${ }^{10,11}$. In SMP-related open literature, various experimental results provide loss factors values at glass transition. The typical values which are reported vary between $0.5^{12}$ and more than $2.5{ }^{13}$ most of them being between 1 and $2^{14-17}$. This intrinsic property has been investigated for the design of composite structures for damping applications in a previous work of Butaud et al. ${ }^{18}$ : a sandwich structure composed of aluminum skins and SMP core was designed and the ability of the SMP to reach very high loss factor values at glass transition was used to control the wave propagation. Results and perspectives are recalled in section 2 of this paper, whose objective consists in pushing the boundaries of this previous study where an awesome damping was observed at the cost of a decrease of the structure stiffness. Instead of applied an homogeneous temperature control of the sandwich, we propose here to control the SMP core with a non-homogeneous temperature field in order to find a compromise between stiffness and damping.

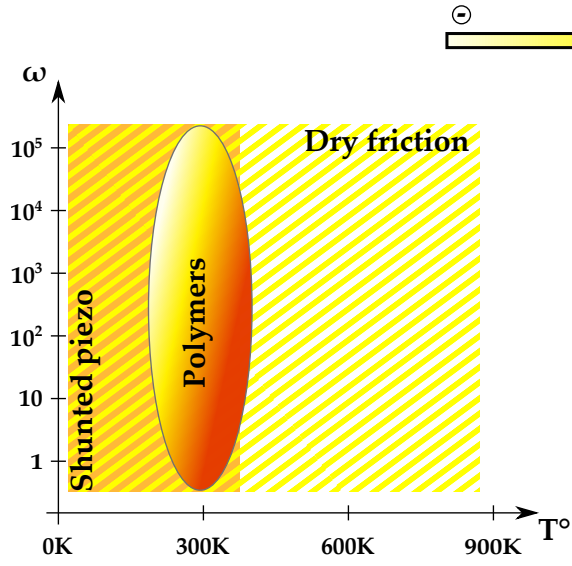

(a)

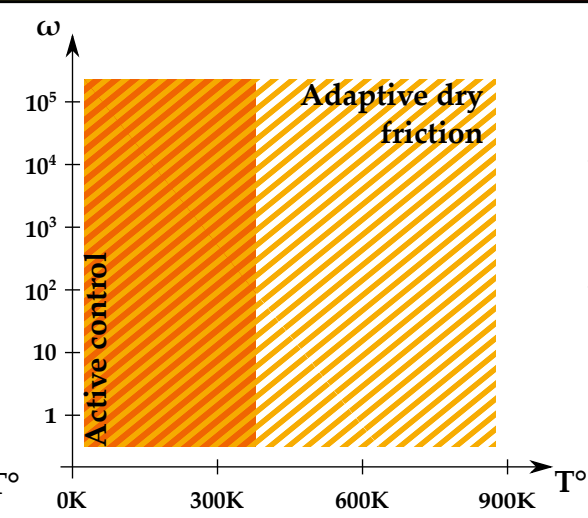

(b)

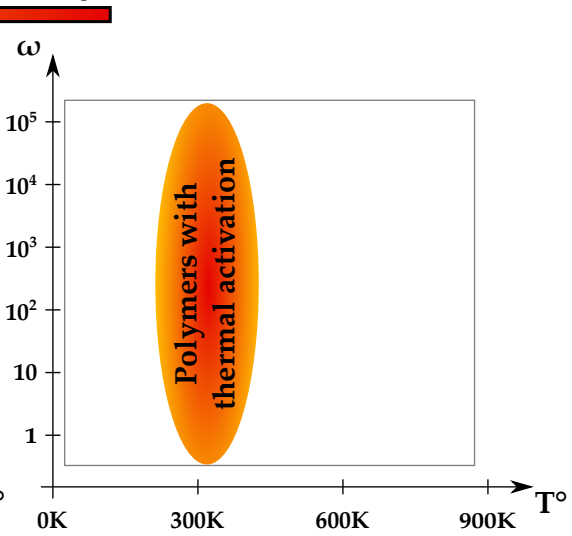

(c)

Figure 1. (a) Passive damping, (b) active damping, (c) thermal adaptive structure proposed in the paper.

The organization of this paper is as follows. The damping properties of the Shape Memory Polymer core sandwich are described in Section 2. Section 3 shows the tuning strategy of the SMP damping properties by the non-homogeneous temperature field in order to obtain a stiffness/damping compromise. The results of this approach are presented in Section 4. Section 5 gives some final conclusions and remarks.

\section{DAMPING PROPERTIES OF SMP CORE SANDWICH}

Elaboration procedures, mechanical characterization, and modelling of the viscoelastic behavior of the SMP of interest, can be found in Butaud et al. ${ }^{19}$

The tBA/PEGDMA, studied by Srivastava et al. ${ }^{20}$ is chosen for this study. It is elaborated at the FEMTOST Department of Applied Mechanics following the procedure described in Yakacki et al. ${ }^{21}$ The SMP has been synthesized by manually mixing $95 \mathrm{wt} \%$ of tBA with $5 \mathrm{wt} \%$ of the crosslinking agent PEGDMA, and $0.5 \mathrm{wt} \%$ of the total weight of DMPA photoinitiator. The dynamic mechanical properties of the SMP have been experimentally measured, a viscoelastic model allowing the description of the rheological properties of the tBA/PEGDMA has been proposed and implemented in a FE software for computing the vibration response of a sandwich structure embedding a SMP layer ${ }^{22}$ (see Fig.2). This composite sandwich has been experimentally and numerically studied. The sandwich was in free-free conditions, a broadband random excitation was applied between 100 and $10000 \mathrm{~Hz}$. The details of the experimental tests and the damping control of the structure can be found in Butaud et al. ${ }^{18}$ and the main informations are recalled here.

The Fig. 3 illustrates the damping capacities of the SMP, through the frequency response functions of the sandwich composite at four representative temperatures. At $20^{\circ} \mathrm{C}$, the SMP is in the glassy state, it has very large storage modulus $\left(E^{\prime}=2100 \mathrm{MPa}\right)$ but very low damping $(\tan (\delta)=0.01)$. The sandwich structure is then rigid but not damped and the FRF exhibits resonance peaks. At $50^{\circ} \mathrm{C}$, the SMP is close to the glass transition. 


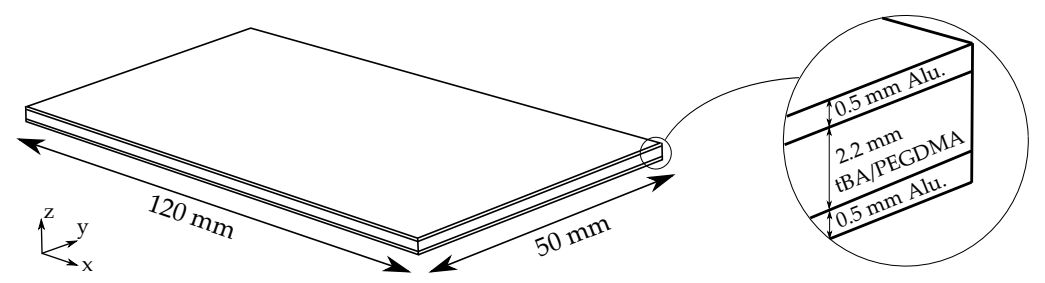

Figure 2. Sandwich structure used in numerical simulation and in experimental tests.

The storage modulus is around $1000 \mathrm{MPa}$, and the loss factor has an average value of 0.2 over the frequency range. Thus the structure heated at $50^{\circ} \mathrm{C}$ is comparable to a classical sandwich composite exhibiting damping effect through viscoelastic behavior of the core. At $80^{\circ} \mathrm{C}$, the tBA/PEGDMA is in the transition state where the material changes from a glassy state to a rubbery state, the material modulus decreases while the loss factor increases up to 2.5 which leads to the cancelling of the sandwich structure resonances. Almost no dynamic effects are visible in the whole frequency range: the curve is completely smoothed, the SMP damping is really efficient. In the rubbery state, at $130^{\circ} \mathrm{C}$, the storage modulus has a low value. The loss factor varies with frequency from 0.2 (at $100 \mathrm{~Hz}$ ) to 2 (at $10 \mathrm{kHz}$ ), hence the sandwich FRF is not as damped as at $80^{\circ} \mathrm{C}$, and some resonances are visible at low frequencies. Fig. 3 shows the impressive damping properties of the tBA/PEGDMA which are furthermore controllable by tuning the temperature of the sandwich core using the rainbow calibration curve. ${ }^{18}$ A good correlation is observed between the experimental results and the simulation results ${ }^{18}$ hence validating of the viscoelastic model chosen for the FE simulation. The drawback of this damping temperature control is the impact on the static stiffness of the structure. Indeed at $20^{\circ} \mathrm{C}$ the SMP is rigid with a storage modulus around $2000 \mathrm{MPa}$ but at $80^{\circ} \mathrm{C}$ the storage modulus is really low around $1 \mathrm{MPa}$. The next section presents, through a numerical study, the proposed strategy to preserve this impressive damping while preserving the static stiffness.

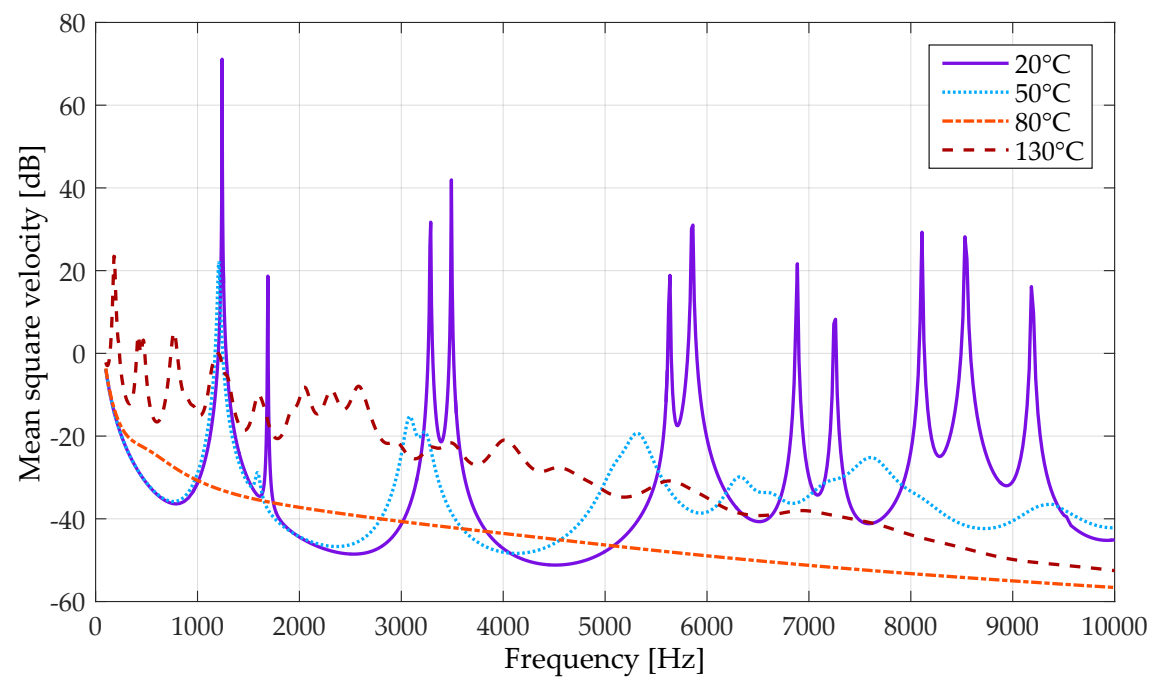

Figure 3. Mean square velocity with respect to z direction, computed on the composite sandwich surface at $20^{\circ} \mathrm{C}, 50^{\circ} \mathrm{C}$, $80^{\circ} \mathrm{C}$ and $130^{\circ} \mathrm{C} .^{18}$

\section{TEMPERATURE FIELD OPTIMIZATION}

Simulating the temperature control of the SMP core in a sandwich structure for vibration damping remains costly since the non-homogeneous temperature field requires the use of a fine 3D FE model. In order to demonstrate the efficiency of the proposed strategy, we focus on a "slice" of the sandwich, corresponding to a 2D composite beam with plane strain assumption. The computational cost is hence drastically reduced, and the concept will 
be easily adapted to 3D models. The beam is clamped at $x=0$ and a distributed harmonic force $\mathrm{f}=1 \mathrm{~N} / \mathrm{m}^{2}$ is applied at $x=200 \mathrm{~mm}$ (Fig.4).

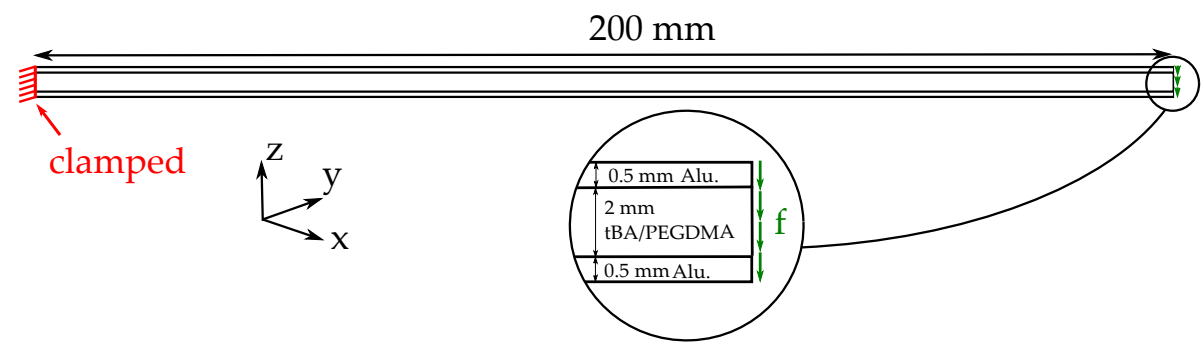

Figure 4. Beam sandwich structure used in numerical simulation.

The Fig. 5 shows the spatial mean displacement of the beam, at $20^{\circ} \mathrm{C}$ and at $77^{\circ} \mathrm{C}$ (the temperature for an optimal damping in the frequency range of interested). At $20^{\circ} \mathrm{C}$, the sandwich beam is rigid but not damped and the dynamic response exhibits four resonance peaks at $72,445,1215$ and $2298 \mathrm{~Hz}$. At $77^{\circ} \mathrm{C}$, no dynamic effect is visible, the curve is completely smoothed. However, at low frequencies, the displacement amplitude is 10 times larger at $77^{\circ} \mathrm{C}$ than at $20^{\circ} \mathrm{C}$. The previous works of Butaud et al. ${ }^{23}$ have highlighted the interest to apply a non-homogeneous temperature field on the SMP core, indeed thanks to an arbitrary non-homogeneous temperature field, a first compromise was found between static stiffness and damping. The work presented here tries to find an optimal non-homogeneous temperature field.

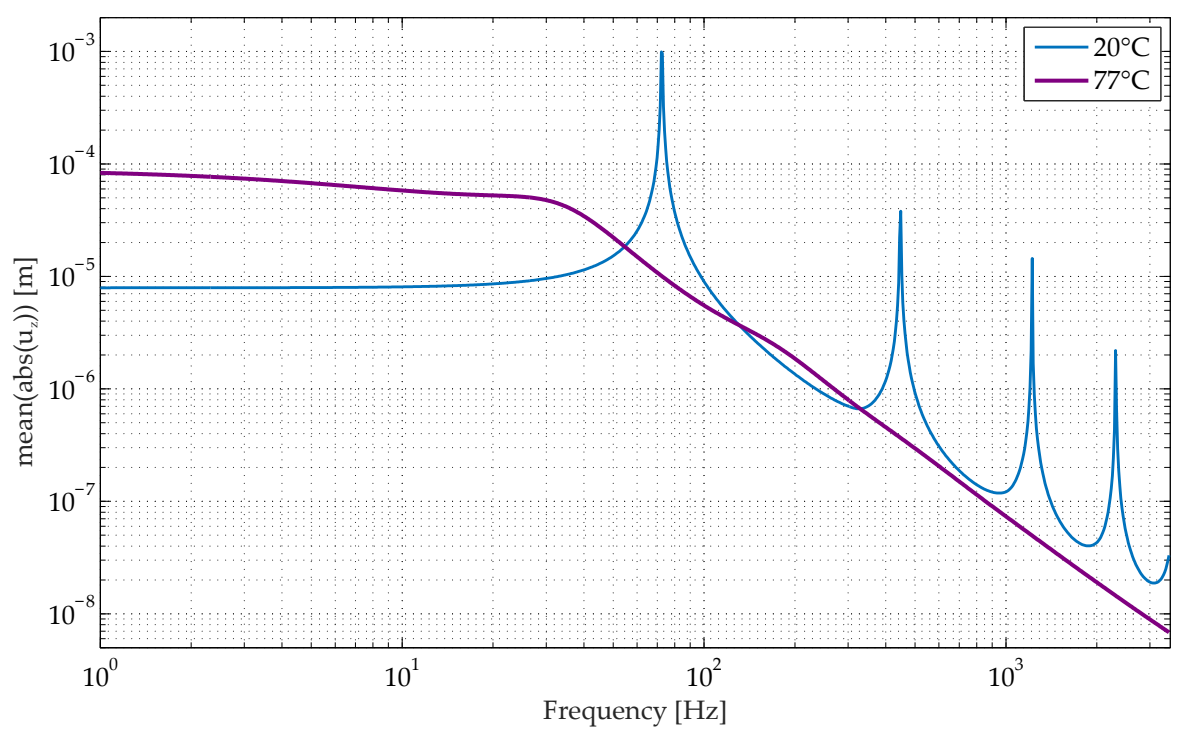

Figure 5. Spatial mean displacement with respect to z direction, computed on the sandwich at $20^{\circ} \mathrm{C}$ and $77^{\circ} \mathrm{C}$.

\subsection{Numerical model definition}

The structure is meshed with 2D quadratic elements with one element in the thickness of the aluminum skins and three elements in the SMP core thickness. The Finite Element model has 1,000 elements and 8,822 degrees of freedom. The materials are assumed to be isotropic. The aluminum material properties for the skins and the SMP core material properties are taken from Butaud et al. ${ }^{18}$ The structure is studied in the $[1-3,500] \mathrm{Hz}$ frequency range of interest. 


\subsection{From elastic strain energy density to temperature field}

The idea proposed in this paper is to define the temperature field on the basis of the elastic strain energy density of the static and dynamic structure states. The elastic strain energy density is defined by

$$
W=\frac{1}{2}(\sigma: \varepsilon)
$$

with $\sigma$ the stress tensor and $\varepsilon$ the strain tensor.

In the following, $W$ is estimated only on the SMP core, a mean is done on the nodes of each $\mathrm{x}$ coordinate. $W$ is evaluated when the SMP is in the glassy state at $20^{\circ} \mathrm{C}$. The quantities of interest are normalized between 0 and 1 for an easier comparison. $W$ will be noted $W_{S}$ for the static state and $W_{D}$ for the dynamic state.

\subsubsection{Static stiffness}

With the objective to ensure a minimum static stiffness to the structure, the static response of the structure has to be considered when searching for a compromise. The static elastic strain energy density of the structure is computed with the FE model. On the basis of this static behavior, the objective consists in defining a temperature field such that the stiffness remains unchanged. This can be achieved only by keeping the zones in which $W_{S}$ is large at low temperature. On zones where the static strain energy density is low, a higher temperature may be used to increase the damping. It has been chosen to define only two temperatures (ie "cold" at $20^{\circ} \mathrm{C}$ and "hot" at $77^{\circ} \mathrm{C}$ ) with an arbitrary threshold $\tau=0.3$ corresponding to $W_{S}=1 / \tau$. Hence all areas where $W_{S}>1 / \tau$ will be kept at $20^{\circ} \mathrm{C}$ while others will be heated at $77^{\circ} \mathrm{C}$. This strategy is illustrated in Fig.6, using the inverse of $W_{S}$ as quantity of interest (hence all areas with $1 / W_{S}>1 / \tau$ will be heated).

The choice has been done, up to now, to establish a discrete temperature field in order to avoid intermediate temperatures as $50^{\circ} \mathrm{C}$ since, as seen in section 2 , these intermediate temperatures are neither interesting in terms of damping nor in terms of stiffness. The non-homogeneous temperature field found here is so $20^{\circ} \mathrm{C}$ for $0 \leqslant \mathrm{x} \leqslant 0.13 \mathrm{~m}$ and $77^{\circ} \mathrm{C}$ for $0.13 \leqslant \mathrm{x} \leqslant 0.2 \mathrm{~m}$.

Obviously, in the practical implementation of the temperature field, no discontinuity will be observed: depending on the thermal properties of the core and skins of the composite, a smoothing of the thermal field will be observed. This point is currently under investigation.

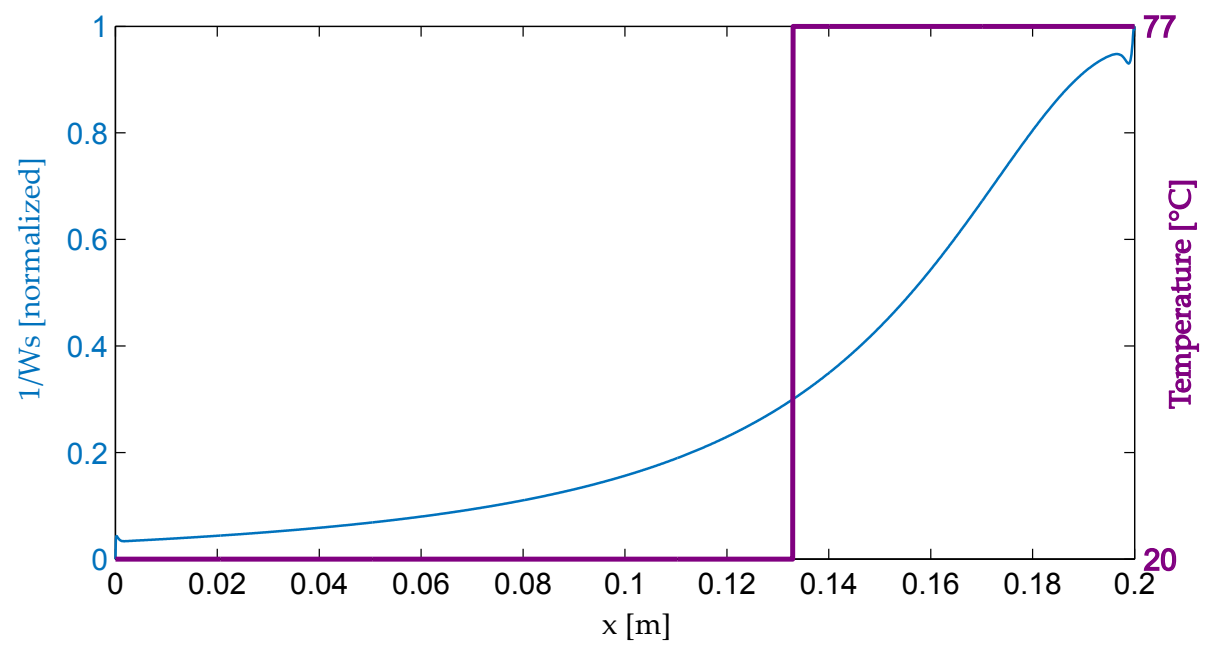

Figure 6. Inverse of the static elastic strain energy density and the associated temperature field with a selected threshold to 0.3 .

\subsubsection{Dynamic damping}

The temperature defined in the previous section is based on the static behavior of the structure. In this section, we propose a similar strategy to define some temperature fields adapted to the dynamic behavior of the structure. The responses of the first four modes are assumed to be representative of the dynamic state. The elastic strain 
energy densities are computed for the four first modes of the structure. On the basis of these dynamic behaviors, the objective consists in defining a temperature field such that the damping is increased. This can be achieved only by applying high temperature on the zones in which $W_{D}$ is large. On zones where the dynamic strain energy density is low, a smaller temperature may be used to increase the stiffness. As previous, it has been chosen to define only two temperatures (ie "cold" at $20^{\circ} \mathrm{C}$ and "hot" at $77^{\circ} \mathrm{C}$ ) with an arbitrary threshold $\tau=0.3$ corresponding to $W_{D}=\tau$. Hence all areas where $W_{D}<\tau$ will be kept at $20^{\circ} \mathrm{C}$ while others will be heated at $77^{\circ} \mathrm{C}$. This strategy is illustrated in Fig.7, using $W_{D}$ as quantity of interest (hence all areas with $W_{D}>\tau$ will be heated).
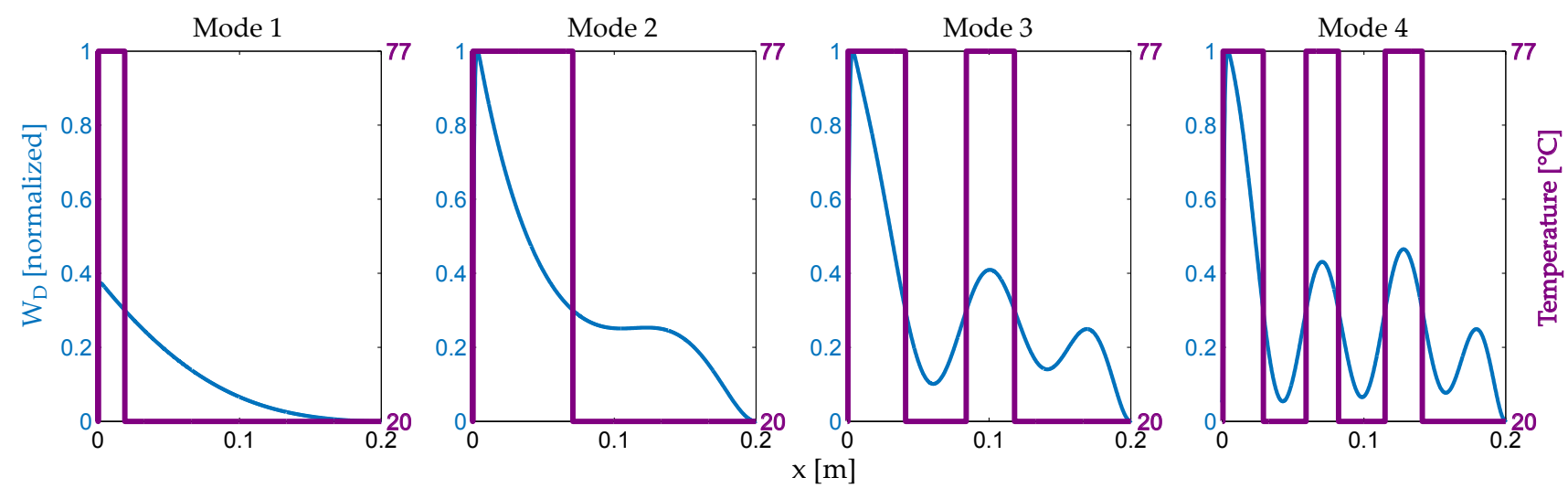

Figure 7. Elastic strain energy density for the fourth first modes, and the associated temperature field with a selected threshold to 0.3 .

\subsubsection{Temperature fields for a compromise between static stiffness and dynamic damping}

We propose now a strategy for combining the temperature fields defined in the two previous sections, in order to achieve a compromise between static stiffness and dynamic damping. The strategy consists in maintaining the $20^{\circ} \mathrm{C}$ temperature where for most cases the temperature is low. Besides, if for the majority, dynamic modes and static included, the temperature is at $77^{\circ} \mathrm{C}$, then the SMP core is heated. Obviously, the temperature field depends on the threshold $\tau$ (until then at 0.3). A high value of $\tau$ corresponds to higher weight on the static rigidity in the decision, while low values of $\tau$ will lead to more damping with lower static rigidity. The discrete temperature fields estimated for $\tau=0.2,0.22,0.25$ and 0.3 are shown in Fig. 8. For $\tau=0.2$, high damping is expected, a large part of the structure has to be heated at $77^{\circ} \mathrm{C}$. When $\tau$ increases, the number of cold zones is growing and the static stiffness is increasing. These temperature fields are used in the next section to check the efficiency of the proposed strategy.
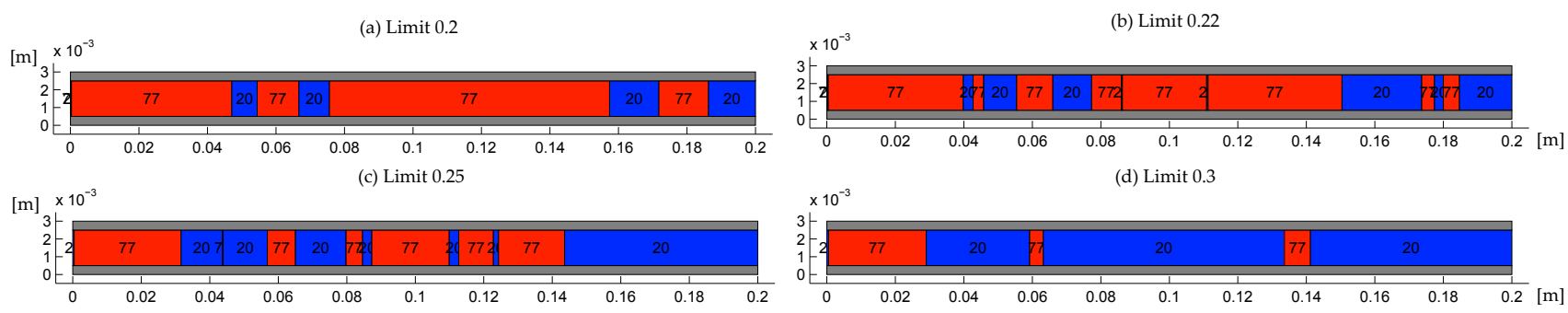

Figure 8. Temperature fields in the beam for different thresholds on the elastic strain energy densities.

\section{RESULTS: STIFFNESS/DAMPING COMPROMISE}

Direct harmonic analyses are performed for the four temperature fields determined previously on the [1-3,500] $\mathrm{Hz}$ frequency range. The Fig.9 presents the results for the two extreme temperatures $20^{\circ} \mathrm{C}$ and $77^{\circ} \mathrm{C}$ and for the four discrete temperature fields associated to each selected threshold. The stiffness/damping compromise obtained is evident: according to the selected threshold, the beam is more or less rigid and more or less damped. 
The 0.2 threshold seems quite interesting, indeed the dynamic response is still very damped while the static response is largely improved compare to the $77^{\circ} \mathrm{C}$ response. The user can make a choice concerning which is the most important for the considered application, stiffness or damping, and adapt the temperature field accordingly. Moreover it is possible to adjust the temperature fields by adding importance criteria on static state or on one mode or another, to control the frequency response.

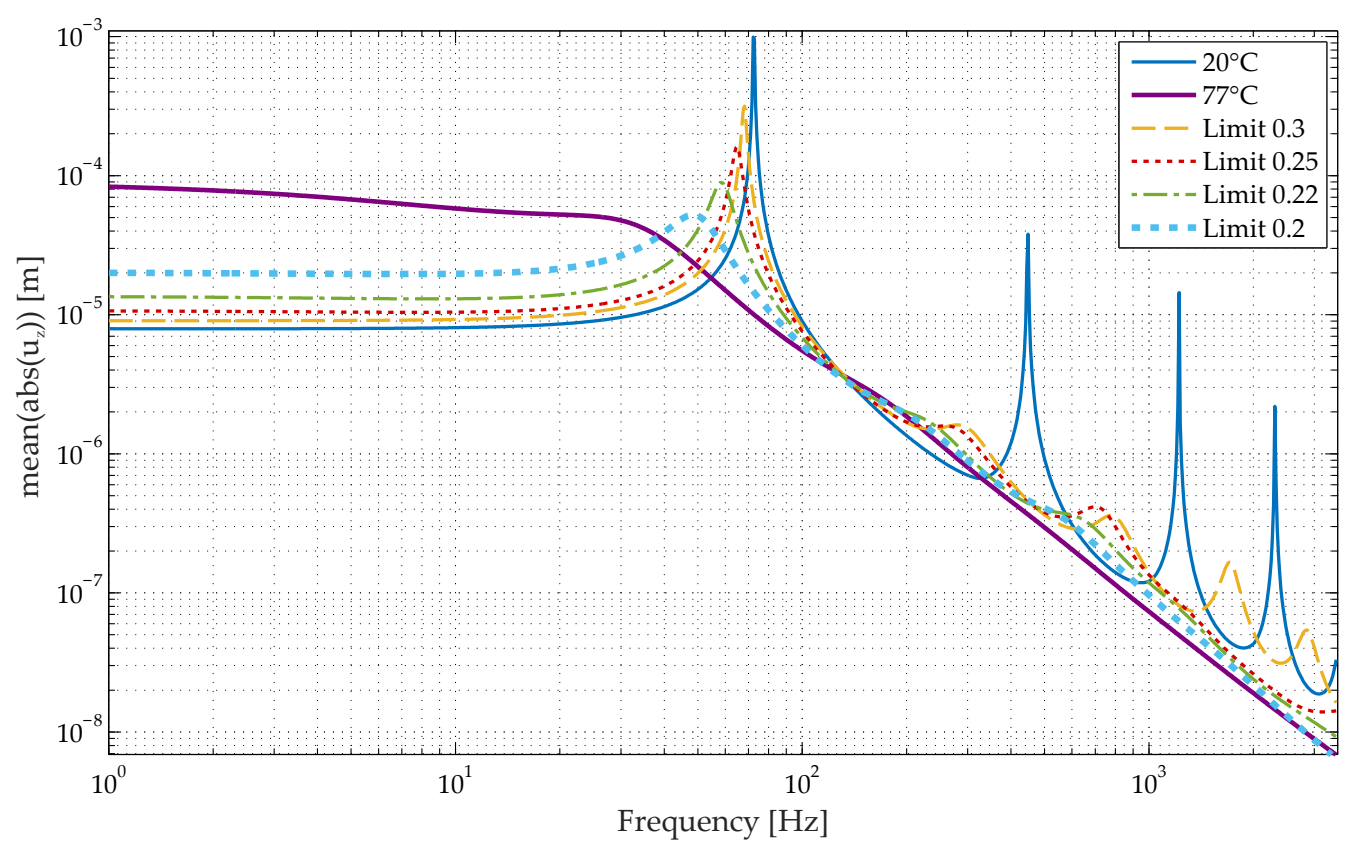

Figure 9. Spatial mean displacement with respect to z direction, estimated on the beam at $20^{\circ} \mathrm{C}, 77^{\circ} \mathrm{C}$ and for different thresholds on the elastic strain energy densities.

\section{CONCLUSIONS}

This study highlights a new approach to control the stiffness and the damping thanks to a temperature field in a viscoelastic sandwich core. The methodology which is proposed in this paper is applicable to any viscoelastic material exhibiting frequency - and temperature - dependent high damping properties. The tuning of the stiffness/damping compromise is performed through the elastic strain energy density value. By adjusting the temperature field, the dynamic and static responses are updated and an optimal solution can be found according to the expectations. The structure proposed is adaptive, providing a way to change the composite properties in real time, by playing on the temperature, in order to adapt the structure to its frequency environment. This device opens up news possibilities on the damping and stiffness adaptive control.

\section{ACKNOWLEDGMENTS}

This work has been performed in cooperation with the Labex ACTION program (ANR-11-LABX-0001-01). The authors would like to acknowledge the "Fond Interministériel Unique" that funds the project CLIMA, and the "Bourse L'Oral-UNESCO Pour les Femmes et la Science" that encourages women to make sciences.

\section{REFERENCES}

[1] Rao, M. D., "Recent applications of viscoelastic damping for noise control in automobiles and commercial airplanes," Journal of Sound and Vibration 262(3), 457-474 (2003).

[2] Trindade, M. A., "Experimental analysis of active-passive vibration control using viscoelastic materials and extension and shear piezoelectric actuators," Journal of Vibration and Control, 1077546309356042 (2010). 
[3] Sunar, M. and Rao, S., "Recent advances in sensing and control of flexible structures via piezoelectric materials technology," Applied Mechanics Reviews 52(1), 1-16 (1999).

[4] Bouaziz, H., Peyret, N., Abbes, M. S., Chevallier, G., and Haddar, M., "Vibration reduction of an assembly by control of the tightening load," International Journal of Applied Mechanics 8(06), 1650081 (2016).

[5] Trindade, M., Benjeddou, A., and Ohayon, R., "Piezoelectric active vibration control of damped sandwich beams," Journal of Sound and Vibration 246(4), 653-677 (2001).

[6] Gaul, L. and Nitsche, R., "Friction control for vibration suppression," Mechanical Systems and Signal Processing 14(2), 139-150 (2000).

[7] Collet, M., Ouisse, M., and Tateo, F., "Adaptive metacomposites for vibroacoustic control applications," Sensors Journal, IEEE 14(7), 2145-2152 (2014).

[8] Tateo, F., Collet, M., Ouisse, M., and Cunefare, K., "Design variables for optimizing adaptive metacomposite made of shunted piezoelectric patches distribution," Journal of Vibration and Control, 1077546314545100 (2014).

[9] Hager, M. D., Bode, S., Weber, C., and Schubert, U. S., "Shape memory polymers: past, present and future developments," Progress in Polymer Science 49, 3-33 (2015).

[10] Tsai, Y., Tai, C.-h., Tsai, S.-J., and Tsai, F.-J., "Shape memory effects of poly (ethylene terephthalate-coethylene succinate) random copolymers," European Polymer Journal 44(2), 550-554 (2008).

[11] Barwood, M. J., Breen, C., Clegg, F., and Hammond, C. L., "The effect of organoclay addition on the properties of an acrylate based, thermally activated shape memory polymer," Applied Clay Science 102, 41-50 (2014).

[12] Biju, R. and Nair, C. R., "Synthesis and characterization of shape memory epoxy-anhydride system," Journal of Polymer Research 20(2), 1-11 (2013).

[13] Ortega, A. M., Kasprzak, S. E., Yakacki, C. M., Diani, J., Greenberg, A. R., and Gall, K., "Structureproperty relationships in photopolymerizable polymer networks: Effect of composition on the crosslinked structure and resulting thermomechanical properties of a (meth) acrylate-based system," Journal of applied polymer science 110(3), 1559-1572 (2008).

[14] Tandon, G., Goecke, K., Cable, K., and Baur, J., "Durability assessment of styrene-and epoxy-based shapememory polymer resins," Journal of Intelligent Material Systems and Structures 20(17), 2127-2143 (2009).

[15] Xie, T. and Rousseau, I. A., "Facile tailoring of thermal transition temperatures of epoxy shape memory polymers," Polymer 50(8), 1852-1856 (2009).

[16] Ellson, G., Di Prima, M., Ware, T., Tang, X., and Voit, W., "Tunable thiol-epoxy shape memory polymer foams," Smart Materials and Structures 24(5), 055001 (2015).

[17] Butaud, P., Placet, V., Klesa, J., Ouisse, M., Foltête, E., and Gabrion, X., "Investigations on the frequency and temperature effects on mechanical properties of a shape memory polymer (veriflex)," Mechanics of Materials 87, 50-60 (2015).

[18] Butaud, P., Foltête, E., and Ouisse, M., "Sandwich structures with tunable damping properties: On the use of shape memory polymer as viscoelastic core," Composite Structures 153, 401-408 (2016).

[19] Butaud, P., Ouisse, M., Placet, V., and Foltête, E., "Experimental investigations on viscoelastic properties of a shape memory polymer," in [ASME 2014 Conference on Smart Materials, Adaptive Structures and Intelligent Systems], V001T01A029-V001T01A029, American Society of Mechanical Engineers (2014).

[20] Srivastava, V., Chester, S. a., and Anand, L., "Thermally actuated shape-memory polymers: Experiments, theory, and numerical simulations," Journal of the Mechanics and Physics of Solids 58(8), 1100-1124 (2010).

[21] Yakacki, C. M., Shandas, R., Lanning, C., Rech, B., Eckstein, A., and Gall, K., "Unconstrained recovery characterization of shape-memory polymer networks for cardiovascular applications," Biomaterials 28(14), 2255 - 2263 (2007).

[22] Butaud, P., Ouisse, M., Foltête, E., and Rogueda-Berriet, C., "Smp-based solution for structural damping," in [NOVEM 2015 - Noise and Vibration - Emerging Technologies], 8 (apr 2015).

[23] Butaud, P., Ouisse, M., and Foltête, E., "A smp core sandwich composite with tunable damping properties," in [22nd International Congress of Sound and Vibration (ICSV22)], 7 (jul 2015). 